\title{
Evaluation of Depression and Anxiety, and their Relationships with Insomnia, Nightmare and Demographic Variables in Medical Students
}

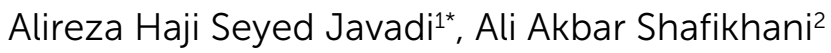 \\ ${ }^{1}$ MD. of Psychiatry, Associate Professor, Department of Psychiatry, Faculty of Medicine, Qazvin University of Medical Sciences, Qazvin, Iran \\ ${ }^{2}$ Department of Occupational Health Engineering, Faculty of Health, Qazvin University of Medical Sciences, Qazvin, Iran
}

\begin{abstract}
Researchers showed comorbidity of sleep disorders and mental disorders. The current study aimed to evaluate depression and anxiety and their relationship with insomnia, nightmare and demographic variables in the medical students of Qazvin University of Medical Sciences in 2015. The study population included 253 medical students with the age range of 18 - 35 years. Data were gathered using Beck depression inventory, Cattle anxiety, and insomnia and nightmare questionnaires and were analyzed by proper statistical methods (independent T-test, Chi-square test and Spearman correlation coefficient $(\mathrm{P}<0.05)$. Among the participants, 126 (49.6\%) subjects had depression and 108 (42.5\%) anxiety. The prevalence of depression and anxiety among the subjects with lower family income was significantly higher $(X 2=6.75, P=.03$ for depression and $X 2=27.99$, $\mathrm{P}<0.05$ for anxiety). There was a close relationship between depression with sleep-onset difficulty, difficulty in awakening and daily sleep attacks, and also between anxiety with sleep-onset difficulty and daily tiredness $(P<0.05)$. In addition, there was a close relationship between depression and anxiety with nightmare; $16.2 \%$ of the subjects with depression and $26.5 \%$ of the ones with anxiety experienced nightmares. Results showed a relationship between nightmare, insomnia and level of family income with increasing depression and anxiety in the medical students. These results can help to perform the preventive mental health program in the medical students.
\end{abstract}

Keywords: Depression; Anxiety; Insomnia; medical students

\section{INTRODUCTION}

In different studies, medical education was identified as a stressful activity and high level of stress in medical students was approved (Momayyezi, Fallahzadeh, \& Momayyezi, 2016). Passing through pre-clinical

\footnotetext{
*Correspondence: ahsjavadi@qums.ac.ir

Alireza Haji Seyed Javadi, 22 Bahman Hospital of Qazvin University of Medical Sciences, Qazvin, Iran

Phone: +98.2833565712 Fax: +98.2833565825
}

Received: 31 December 2017 Accepted: 03 February 2018

\section{Sleep and Hypnosis \\ Journal homepage: \\ www.sleepandhypnosis.org \\ ISSN: 2458-9101 (Online)}

educations to clinical educations is one of the critical stages of mental health in medical students, which provides conditions for depression and anxiety (Ighodaro, Stefanovics, Makanjuola, \& Rosenheck, 2015). These mental disorders may cause further problems and affect their performance. Different studies evaluated the high level of anxiety and depression in the medical students using different tools (lqbal, Gupta, \& Venkatarao, 2015), Most likely, this anxiety and depression are related to the scientific, financial and social requirements of the university atmosphere (Jadoon, Yaqoob, Raza, Shehzad, \& Zeshan, 2010; Tyssen, Vaglum, Grønvold, \& Ekeberg, 2001). Hence, determining the prevalence of anxiety and depression and their relationship with sociodemographic 
variables are of great importance (Haji SeyedJavadi \& Shafikhani, 2017).

On the other hand, epidemiological studies performed in Western Europe, USA, Japan have reported a prevalence of insomnia-related symptoms ranging from $10 \%$ to $48 \%$ (Palatty, Fernandes, Suresh, \& Baliga, 2011). Medical students are one subgroup of the general population who appear to be especially vulnerable to poor sleep, perhaps due to the long duration and high intensity of study, clinical duties that include overnight on-call duties, work that can be emotionally challenging, and lifestyle choices (Azad et al., 2015; Palatty et al., 2011).

Insomnia and nightmare are interacting with various factors, one of the most important of which is depression and anxiety (Cutler, 2016; Nadorff, Nazem, \& Fiske, 2011; Sundbom, Malinovschi, Lindberg, Alving, \& Janson, 2016). Studies showed that continuous nightmares may lead to different disorders and affect the performance and occupational status of the person and intensify depression and anxiety in him/her. If such a hypothesis proved, nightmares can act as an initial indication of the onset of depression and anxiety (Kelly, 2016; Krakow, Haynes, Warner, \& Melendrez, 2007; Levin \& Fireman, 2002; Nakajima et al., 2014).

But the challenging issue is which of the symptoms of sleep is more associated with depression and anxiety. There are some disagreements in this regard which need more investigations. According to some studies, these problems are sleep-onset difficulty and difficulty maintaining sleep (David Nutt \& Paterson, 2008; Hayley et al., 2014). Other studies believed that obstructive sleep apnea, with larger effect size, is the main cause of sleep disorder in association with depression (Harris, Glozier, Ratnavadivel, \& Grunstein, 2009; Rezaeitalab, Moharrari, Saberi, Asadpour, \& Rezaeetalab, 2014). Identifying each of the factors can affect the diagnosis and treatment of depression and anxiety. If nightmares are associated with depression and anxiety, mood disorders can be investigated in the students. Identifying such relationships with mental disorders is of great importance; such clues can significantly help to perform the preventive mental health program in the medical students. The purpose of this study was to evaluate anxiety and depression and its relation to insomnia, nightmares and demographic variables in medical students of Qazvin University of Medical Sciences in 1394.

\section{METHODS}

The current cross-sectional study was conducted in Qazvin University of Medical Sciences in June, 2015. The research protocol was approved by the Ethics Review Committee on Human Research of the University of Qazvin. Before distributing the questionnaires, the oral informed consent was obtained from all participants and they were assured regarding the confidentiality of the information. The inclusion criterion were at least six months presence in the university and residence in the dormitories of Qazvin University of Medical Sciences. The exclusion criterion was severe physical illness at the time of intervention. In addition, those who had a serious accident in the past months were also excluded. The samples were selected using stratified random sampling. So, first, the total number of students each of the buildings belonging to this collection was determined, then, according to the number of students, from each building a number of samples were randomly selected. The sampling team moved to each floor of the building in clockwise direction and they chose each room one in between. In the event that the residents were not present or were not willing to cooperate, the adjoining room was selected. A total of 253 people were included in the study. After explaining the study goals to the participants and obtaining the oral consent, the data were collected through the questionnaires. First of all, sociodemographic data (age, gender, marital status, place of residence, level of education and income), medical records and other data were collected and recorded through specific forms. Depression symptoms were evaluated using Beck depression inventory and the anxiety symptoms were assessed by Cattle anxiety questionnaire. The Beck questionnaire involved 21 four-option multiple choice questions, each item score ranging 0-3 shows the severity of depression (Özcan, Dursun, \& Cicek, 2015), with the maximum score of 63 , which $0-15$ indicated the normal status, 16-30 slight depression, 31-46 moderate 
depression and 47-63 severe depression (Özcan et al., 2015; Rosner, 2015). Validity and reliability Beck Depression Inventory In previous studies have been approved with Cronbach a of 0.83 to 0.85 (Hojat, Shapurian, \& Mehryar, 1986a, 1986b). The Cattle anxiety test is a 40 -item questionnaire with an interval scale which indicates the general anxiety, quantitatively (Hajseyed Javadi, Ziaee, Yazdi, Ebrahimabadi, \& Shafikhani, 2017). The validity of its Persian version has been determined and reliability has been reported from 0.65 to 0.85 (Dadsetan \& Mansour 1989). Based on Kaplan and Sadock textbook of psychiatry and considering the questionnaires used in the previous epidemiologic studies, the sleep questionnaire was designed and developed based on the study purpose (R. Li, Wing, Ho, \& Fong, 2002; S. X. Li, Zhang, Li, \& Wing, 2010; Sadock \& Sadock, 2011). The validity and reliability of this researcher-designed questionnaire was approved with the Cronbach's alpha of 0.836 . This questionnaire includes 14 items evaluating a wide spectrum of sleep clinical features such as sleeponset difficulty, difficulty maintaining sleep, early morning awakening, snoring, restless sleep, dry mouth, nightmare, morning headache and daily tiredness. This questionnaire investigates all sleep signs during the recent 12 months.
The subjects were asked to score the frequency of sleep disorders within the last year based on a five-point scale ( $0=$ none, $1=$ less than 'once in a month, $2=$ once or twice in a month, $3=$ once or twice in a week, $4=$ three times or more in a week). Regarding the nightmare item in the current study, the term "nightmare" had no specific definition in Iran. This item involved four answers as: no nightmare in the previous month, less than once a week, once or twice a week, three times or a week or more. The collected data were analyzed using SPSS ver. 22. Data were presented for the categorical variables; mean and standard deviation for the continuous variables in frequency and percentage. To compare the continuous variables, the independent T-test, and to compare the categorical variables the Chi-square test were used. The relationship between sleep signs, depression and anxiety were assessed using Spearman correlation coefficient $(P<0.05)$.

\section{RESULTS}

A study population, consisted of 81 (31.9\%) males and $172(67.7 \%)$ females with the mean age of $22.32 \pm 2.85$ years (ranged 18-35), were assigned to the study; 126 (49.6\%) and 108 (42.5\%) subjects had depression and anxiety,

Table 1. The Relationship of Sociodemographic Features with Anxiety and Depression in the Students

\begin{tabular}{|c|c|c|c|c|c|c|}
\hline \multirow{2}{*}{ Variable } & \multicolumn{2}{|c|}{ Depression } & \multirow{2}{*}{ P-value } & \multicolumn{2}{|c|}{ Anxiety } & \multirow{2}{*}{ P-value } \\
\hline & Yes & No & & Yes & No & \\
\hline \multicolumn{7}{|l|}{ Gender } \\
\hline Male & $41(16.2 \%)$ & $40(15.8 \%)$ & 0.859 & $34(13.4 \%)$ & $47(18.6 \%)$ & 0.875 \\
\hline Female & $85(33.6 \%)$ & $87(34.4 \%)$ & & $74(13.4 \%)$ & $98(38.7 \%)$ & \\
\hline \multicolumn{7}{|l|}{ Age } \\
\hline Mean (SD) & $22.36(2.87)$ & $22.29(2.83)$ & 0.837 & $22.45(2.94)$ & $22.23(2.78)$ & 0.546 \\
\hline \multicolumn{7}{|l|}{ Marital status } \\
\hline Single & $114(45.1 \%)$ & $113(44.7 \%)$ & 0.694 & $93(36.8 \%)$ & $134(53 \%)$ & 0.102 \\
\hline Married & $12(4.7 \%)$ & $14(5.5 \%)$ & & $15(5.9 \%)$ & $11(4.3 \%)$ & \\
\hline \multicolumn{7}{|l|}{ Education level } \\
\hline Sciences & $41(16.2 \%)$ & $42(16.6 \%)$ & 0.23 & $40(15.8 \%)$ & $43(17 \%)$ & 0.08 \\
\hline Physiopathology & $24(9.5 \%)$ & $16(6.3 \%)$ & & $8(3.2 \%)$ & $32(12.6 \%)$ & \\
\hline Training & $23(9.1 \%)$ & $35(13.8 \%)$ & & $23(9.1 \%)$ & $35(13.8 \%)$ & \\
\hline Internship & $38(15 \%)$ & $34(13.4 \%)$ & & $37(14.7 \%)$ & $35(13.8 \%)$ & \\
\hline \multicolumn{7}{|l|}{ Place of residence } \\
\hline Dormitory & $101(39.9 \%)$ & $89(35.2 \%)$ & 0.154 & $86(34 \%)$ & $104(41.1 \%)$ & 0.352 \\
\hline In family & $14(5.5 \%)$ & $24(9.5 \%)$ & & $13(5.1 \%)$ & $25(9.9 \%)$ & \\
\hline Private home & $11(4.3 \%)$ & $14(5.5 \%)$ & & $9(3.6 \%)$ & $16(6.3 \%)$ & \\
\hline \multicolumn{7}{|l|}{ Family income } \\
\hline Less than 430 US\$ & $74(31.5 \%)$ & $46(19.6 \%)$ & 0.034 & $74(31.5 \%)$ & $46(19.6 \%)$ & $<0.05$ \\
\hline 430-570US\$ & $35(14.9 \%)$ & $39(16.6 \%)$ & & $17(7.2 \%)$ & $57(24.3 \%)$ & \\
\hline >570US\$ & $17(7.2 \%)$ & $24(10.2 \%)$ & & $17(7.2 \%)$ & $24(10.2 \%)$ & \\
\hline
\end{tabular}


Table 2. The Relationship between Sleep Disorder Symptoms with Depression and Anxiety in the

\begin{tabular}{|c|c|c|c|c|}
\hline \multirow{2}{*}{ Variables } & \multicolumn{2}{|c|}{ Depression } & \multicolumn{2}{|c|}{ Anxiety } \\
\hline & $\mathbf{r}$ & P-value & $\mathbf{r}$ & P-value \\
\hline \multicolumn{5}{|l|}{ Insomnia symptoms } \\
\hline Sleep-onset difficulty & 0.492 & 0 & 0.568 & 0 \\
\hline Difficulty maintaining sleep & 0.063 & 0.315 & 0.116 & 0.066 \\
\hline Early morning awakening & 0.073 & 0.248 & 0.82 & 0.161 \\
\hline Restless sleep & 0.041 & 0.512 & 0.071 & 0.261 \\
\hline \multicolumn{5}{|l|}{ Obstructive sleep apnea } \\
\hline Dry mouth & -0.011 & 0.856 & 0.038 & 0.546 \\
\hline Nightly sweating & 0.036 & 0.574 & 0.071 & 0.262 \\
\hline Mouth breathing & 0.082 & 0.194 & 0.112 & 0.075 \\
\hline Snoring & 0.053 & 0.398 & 0.103 & 0.103 \\
\hline \multicolumn{5}{|c|}{ Problems associated with daily consequences } \\
\hline Daily tiredness & 0.022 & 0.726 & 0.4 & 0 \\
\hline Morning headaches & 0.041 & 0.512 & 0.071 & 0.261 \\
\hline Early morning awakening & 0.317 & 0 & 0.118 & 0.062 \\
\hline Daily sleep attacks & 0.368 & 0 & 0.05 & 0.429 \\
\hline
\end{tabular}

Spearman correlation coefficient

Table 3. The Relationship Between Nightmare With Depression and Anxiety in the Students

\begin{tabular}{|c|c|c|c|c|c|}
\hline \multirow[b]{2}{*}{ Variable } & \multicolumn{4}{|c|}{ Nightmare } & \multirow[b]{2}{*}{$\mathrm{P}$-value } \\
\hline & Never & $\begin{array}{l}\text { Less Than Once } \\
\text { in a Week }\end{array}$ & $\begin{array}{l}\text { One to Three Times } \\
\text { in a Week }\end{array}$ & $\begin{array}{l}\text { Three Times or More } \\
\text { in a Week }\end{array}$ & \\
\hline \multicolumn{6}{|c|}{ Depression } \\
\hline Yes & $85(33.6 \%)$ & $21(8.3 \%)$ & $17(6.7 \%)$ & $3(1.2 \%)$ & 0.001 \\
\hline No & 99(39.1\%) & $26(10.3 \%)$ & $1(.4 \%)$ & $1(.4 \%)$ & \\
\hline \multicolumn{6}{|l|}{ Anxiety } \\
\hline Yes & $41(16.2 \%)$ & $47(18.6 \%)$ & $17(6.7 \%)$ & $3(1.2 \%)$ & 0.05 \\
\hline No & $143(56.3 \%)$ & $0(0 \%)$ & $1(.4 \%)$ & $1(.4 \%)$ & \\
\hline
\end{tabular}

respectively. Table 1 shows the frequency of mental disorders (anxiety and depression) considering sociodemographic features (age, gender, marital status, education level, place of residence and family income) in the subjects.

Among the sociodemographic variables, the prevalence of depression and anxiety were significantly higher in the subjects with family income less than 430 USS $\left(X^{2}=6.75, P=0.03\right.$ for the depression and $X^{2}=27.99$, $\mathrm{P}<0.05$ for the anxiety) (Table 1 ). There was no significant relationship between the other variables.

The prevalence of insomnia among the medical students was 12 (44.3\%). Results of the Chi-square test showed that the number of subjects with depression and insomnia was significantly higher than the ones with depression without insomnia [73 (28.9\%) subjects with depression and insomnia vs. $53(20.9 \%)$ subjects with depression without insomnia] $(\mathrm{P}<0.05)$; there was a insignificant relationship between anxiety and insomnia [52 (20.6\%) subjects with anxiety and insomnia vs. 56 (22.1\%) subjects with anxiety without insomnia] $(P<0.284)$. Table 2 shows the relationship between insomnia with depression and anxiety in the students. There was a significant relationship between sleep-onset difficulty, difficulty in awakening and daily sleep attacks with depression symptoms (P-value<0.05). There was also a significant relationship between sleep-onset difficulty, difficulty in awakening and daily tiredness with anxiety. The largest effect size among the sleep symptoms belonged to sleep-onset disorder.

The prevalence of nightmare among the subjects was $27.3 \%$. Table 3 compares the frequency of nightmare among the groups classified based on anxiety and insomnia. There was a significant difference between the scores of anxiety and insomnia among the four groups. 


\section{DISCUSSION}

The current study showed that $49.6 \%$ of medical students presented depression symptoms and $42.5 \%$ had anxiety. These findings were in line with those of the studies conducted in the USA (49\%) (Dyrbye et al., 2007), Beirut (27.63\% and 69\%) (Mehanna \& Richa, 2006) and Iran (Najafi Kalyani, Pourjam, Jamshidi, Karimi, \& Najafi Kalyani, 2013). However, these rates were significantly higher than the ones reported in other studies; for example, in the study by Zakeri et al., the prevalence of depression and anxiety was $29.7 \%$ and $11.5 \%$, respectively (Zakeri, Sedaghat, Motlagh, Ashtiani, \& Ardalan, 2012). Perhaps one of the reasons for these differences is the use of different screening tools in different studies.

The prevalence of insomnia was $44.3 \%$ in the current study, which was similar to that of the study by Veldi et al (Veldi, Aluoja, \& Vasar, 2005). The prevalence of nightmare, with the frequency of at least once or more in a week, was $8.7 \%$. This rate was rather similar to those of other studies that used similar tools (1\%-7\%) (S. X. Li et al., 2010; Schredl, 2010).

The results of this study showed that not only the symptoms of insomnia, but also nightmares were associated with an increase in depression and anxiety scores. Researchers showed that people with depression and anxiety had extreme concern and preoccupation about their problems; hence, their emotions were aroused and affected by insomnia and nightmare (Basta, Chrousos, Vela-Bueno, \& Vgontzas, 2007; Nakajima et al., 2014). These findings can lead to the conclusion that each of insomnia and nightmare symptoms can act as depression and anxiety risk factors and intensifies it; nightmare can also induce depression and anxiety due to its association with insomnia.

In the current study, there was a significant relationship between nightmare with depression and anxiety; $16.2 \%$ of students with depression and $26.5 \%$ of students with anxiety had experienced nightmares. Studies indicated that $28.4 \%$ of the subjects with depression have experienced nightmare; while, nightmare is experienced in only $3.9 \%$ of healthy subjects (Eller, Aluoja, Vasar, \& Veldi, 2006).

Studies showed a significant relationship between high stress and socio-economic status; these findings encouraged authors of the current study to investigate this issue. In the current study, there was a significant relationship between the level of income with depression and anxiety.

Other studies also showed that people with lower income were more affected by depression and anxiety (Jadoon et al., 2010).

There was a significant relationship between early symptoms of depression and initial insomnia (sleep-onset difficulty) with daily sleepiness in the current study. In contrast to the mentioned relationship, no significant relationship was observed between terminal insomnia (early morning awakening) and middle insomnia (difficulty maintaining sleep) with depression and anxiety. In a study conducted by Eller et al., they obtained similar results (Eller et al., 2006).

Most of the insomnia questionnaires are focused on the frequency of such symptoms instead of evaluating their power. The current study tried to show the correlation rate of each of the symptoms in the mentioned relationship to draw Quantitative attention toward it. Results showed that difficulty in Sleep-onset had the largest correlation rate, among other symptoms associated with depression and anxiety. Of course, such results were almost predictable due to the age range of the students. Studies have shown that in contrast to the adults who have middle and terminal insomnia, the early insomnia is the main symptom among youth (Liu, Uchiyama, Kim, et al., 2000; Liu, Uchiyama, Okawa, \& Kurita, 2000).

There were some limitations in the current study; first, it was a cross-sectional study; hence, a causal link cannot be educed between depression and anxiety with insomnia and nightmare. Second, the current study only evaluated the frequency of nightmare symptoms; therefore, further investigations should be conducted to measure the inconvenience caused by nightmare in a standard format, in addition to measuring the frequency of nightmare. 


\section{CONCLUSIONS}

Results showed a significant relationship between nightmare, insomnia symptoms and level of income with increased depression and anxiety in the medical students. On closer examination the symptoms of insomnia, there was a close relationship between depression with sleeponset difficulty, difficulty in awakening and daily sleep attacks, and also between anxiety with sleep-onset difficulty and daily tiredness; hence, it is essential to consider these factors in therapy and prevention methods to prevent the aggravation of symptoms of depression and anxiety. Given the limitations mentioned, further studies are needed (preferably longitudinally) to investigate the causal relationships between mental health problems with symptoms of insomnia and nightmares.

\section{References}

Azad, M. C., Fraser, K., Rumana, N., Abdullah, A. F., Shahana, N., Hanly, P. J., \& Turin, T. C. (2015). Sleep disturbances among medical students: a global perspective. Journal of clinical sleep medicine: JCSM: official publication of the American Academy of Sleep Medicine, 11(1), 69.

Basta, M., Chrousos, G. P., Vela-Bueno, A., \& Vgontzas, A. N. (2007). Chronic insomnia and the stress system. Sleep medicine clinics, 2(2), 279-291.

Cutler, A. J. (2016). The role of insomnia in depression and anxiety: its impact on functioning, treatment, and outcomes. J Clin Psychiatry, 77, e1010.

Dadsetan, P., \& Mansour, M. (1989). Mental disorders: Tehran: Darya.

David Nutt, D., \& Paterson, L. (2008). Sleep disorders as core symptoms of depression. Dialogues Clin Neurosci, 10, 329336.

Dyrbye, L. N., Thomas, M. R., Eacker, A., Harper, W., Massie, F. S., Power, D. V., . . Shanafelt, T. D. (2007). Race, ethnicity, and medical student well-being in the United States. Archives of Internal Medicine, 167(19), 2103-2109.

Eller, T., Aluoja, A., Vasar, V., \& Veldi, M. (2006). Symptoms of anxiety and depression in Estonian medical students with sleep problems. Depression and anxiety, 23(4), 250-256.

Haji SeyedJavadi, A., \& Shafikhani, A. (2017). Evaluation of depression and anxiety in patients with thalassemia: a comparative study. The Journal of Qazvin University of Medical Sciences, 21(2), 21-13.

Hajseyed Javadi, A., Ziaee, A., Yazdi, Z., Ebrahimabadi, N., \& Shafikhani, A. A. (2017). Prevalence of Anxiety and Depression in Diabetic Patients: A Comparative Study. Biotech Health Sci, S(1), e41629. doi:10.5812/bhs.41629

Harris, M., Glozier, N., Ratnavadivel, R., \& Grunstein, R. R. (2009). Obstructive sleep apnea and depression. Sleep medicine reviews, 13(6), 437-444.
Acknowledgment: The author acknowledges the immense help received from the scholars whose articles are cited and included in the reference of this manuscript. The authors are also grateful to the authors /editors/ publishers of all those articles, journals, and books from where the literature for this article has been reviewed and discussed.

Conflict of interest: The authors declare no conflict of interest.

Informed consent: Informed consent was obtained from all the participants included in the study.

Funding: The authors declare that the current study was not financially supported by any institution or organization.

Hayley, A. C., Skogen, J. C., Sivertsen, B., Wold, B., Berk, M., Pasco, J. A., \& Øverland, S. (2014). Symptoms of Depression and Difficulty Initiating Sleep from Early Adolescence to Early Adulthood: A Longitudinal Study. Sleep, 38(10), 1599-1606.

Hojat, M., Shapurian, R., \& Mehryar, A. H. (1986a). Dimensionality of the short form of the Beck Depression Inventory: a study with Iranian college students. Psychol Rep, 59(3), 1069-1070. doi:10.2466/pro.1986.59.3.1069

Hojat, M., Shapurian, R., \& Mehryar, A. H. (1986b). Psychometric properties of a Persian version of the short form of the Beck Depression Inventory for Iranian college students. Psychol Rep, 59(1), 331-338. doi:10.2466/pr0.1986.59.1.331

Ighodaro, A., Stefanovics, E., Makanjuola, V., \& Rosenheck, R. (2015). An assessment of attitudes towards people with mental illness among medical students and physicians in Ibadan, Nigeria. Academic Psychiatry, 39(3), 280-285

Iqbal, S., Gupta, S., \& Venkatarao, E. (2015). Stress, anxiety \& depression among medical undergraduate students $\&$ their socio-demographic correlates. The Indian journal of medical research, 141(3), 354.

Jadoon, N. A., Yaqoob, R., Raza, A., Shehzad, M. A., \& Zeshan, S. (2010). Anxiety and depression among medical students: a cross-sectional study. JPMA. The Journal of the Pakistan Medical Association, 60(8), 699-702.

Kelly, W. E. (2016). Some Personality Characteristics of College Students Reporting Frequent Nightmares. Sleep and Hypnosis, 18(3), 69-73.

Krakow, B., Haynes, P. L., Warner, T. D., \& Melendrez, D. (2007). Clinical sleep disorder profiles in a large sample of trauma survivors: An interdisciplinary view of posttraumatic sleep disturbance. Sleep and Hypnosis, 9(1), 6.

Levin, R., \& Fireman, G. (2002). Nightmare prevalence, nightmare distress, and self-reported psychological disturbance. SLEEPNEW YORK-, 25(2), 205-212 
Li, R., Wing, Y., Ho, S., \& Fong, S. (2002). Gender differences in insomnia-a study in the Hong Kong Chinese population. Journal of Psychosomatic Research, 53(1), 601-609.

Li, S. X., Zhang, B., Li, A. M., \& Wing, Y. K. (2010). Prevalence and correlates of frequent nightmares: a community-based 2-phase study. Sleep, 33(6), 774-780.

Liu, X., Uchiyama, M., Kim, K., Okawa, M., Shibui, K., Kudo, Y., . . . Ogihara, R. (2000). Sleep loss and daytime sleepiness in the general adult population of Japan. Psychiatry research, 93(1), $1-11$.

Liu, X., Uchiyama, M., Okawa, M., \& Kurita, H. (2000). Prevalence and correlates of self-reported sleep problems among Chinese adolescents. Sleep: Journal of Sleep Research \& Sleep Medicine.

Mehanna, Z., \& Richa, S. (2006). [Prevalence of anxiety and depressive disorders in medical students. Transversal study in medical students in the Saint-Joseph University of Beirut]. Encephale., 32(6 Pt 1), 976-982.

Momayyezi, M., Fallahzadeh, H., \& Momayyezi, M. (2016). Clinical education stressors in medical trainees in Shahid Sadoughi University of Medical Sciences, Yazd. Journal of Advances in Medical Education \& Professionalism, 4(1), 8.

Nadorff, M. R., Nazem, S., \& Fiske, A. (2011). Insomnia symptoms, nightmares, and suicidal ideation in a college student sample. Sleep, 34(1), 93-98.

Najafi Kalyani, M., Pourjam, E., Jamshidi, N., Karimi, S., \& Najafi Kalyani, V. (2013). Survey of stress, anxiety, depression and selfconcept of students of Fasa University of medical sciences, 2010. Journal of Fasa University of Medical Sciences, 3(3), 235240.

Nakajima, S., Inoue, Y., Sasai, T., Okajima, I., Komada, Y., Nomura, T., \& Takahashi, K. (2014). Impact of frequency of nightmares comorbid with insomnia on depression in Japanese rural community residents: a cross-sectional study. Sleep medicine, 15(3), 371-374
Özcan, A., Dursun, A. B., \& Cicek, T. (2015). The comparison of anxiety and depression levels in asthma and COPD patients. The World Allergy Organization Journal, 8(Suppl 1), A51.

Palatty, P. L., Fernandes, E., Suresh, S., \& Baliga, M. (2011). Comparison of Sleep Pattern Between Medical Ald Law Students. Sleep and Hypnosis, 13(1-2), 15-18.

Rezaeitalab, F., Moharrari, F., Saberi, S., Asadpour, H., \& Rezaeetalab, F. (2014). The correlation of anxiety and depression with obstructive sleep apnea syndrome. J Res Med Sci, 19(3), 205-210.

Rosner, R. I. (2015). Beck Depression Inventory (BDI). The Encyclopedia of Clinical Psychology.

Sadock, B. J., \& Sadock, V. A. (2011). Kaplan and Sadock's synopsis of psychiatry: Behavioral sciences/clinical psychiatry: Lippincott Williams \& Wilkins.

Schredl, M. (2010). Nightmare frequency and nightmare topics in a representative German sample. European archives of psychiatry and clinical neuroscience, 260(8), 565-570.

Sundbom, F., Malinovschi, A., Lindberg, E., Alving, K., \& Janson, C. (2016). Effects of poor asthma control, insomnia, anxiety and depression on quality of life in young asthmatics. Journal of Asthma, 53(4), 398-403.

Tyssen, R., Vaglum, P., Grønvold, N. T., \& Ekeberg, Ø. (2001). Factors in medical school that predict postgraduate mental health problems in need of treatment. A nationwide and longitudinal study. Medical education, 35(2), 110-120.

Veldi, M., Aluoja, A., \& Vasar, V. (2005). Sleep quality and more common sleep-related problems in medical students. Sleep medicine, 6(3), 269-275.

Zakeri, M., Sedaghat, M., Motlagh, M. E., Ashtiani, R. T., \& Ardalan, G. (2012). BMI correlation with psychiatric problems among 10-18 years Iranian students. Acta Medica Iranica, 50(3), 177. 